\title{
In vitro metabolism of a nitroderivative of acetylsalicylic acid (NCX4016) by rat liver: LC and LC-MS studies
}

\author{
Marina Carini *, Giancarlo Aldini, Marica Orioli, Roberto Maffei Facino
}

Istituto Chimico Farmaceutico Tossicologico, Viale Abruzzi 42, 20131 Milan, Italy

Received 6 June 2001; received in revised form 17 December 2001; accepted 21 December 2001

\begin{abstract}
The metabolism of a nitroderivative of acetylsalicylic acid, benzoic acid, 2-(acetyloxy)-3-[(nitrooxy)methyl]phenyl ester (NCX4016), the lead compound of a new class of NO-releasing non steroidal-antiinflammatory drugs has been studied in vitro in rat liver subcellular fractions $(\mathrm{S} 9000 \times \mathrm{g}$, microsomes, cytosol). Samples were extracted with $\mathrm{CH}_{3} \mathrm{CN}$ (2 vol.) containing $1 \% \mathrm{H}_{3} \mathrm{PO}_{4}(2 \mathrm{M}$ ), vortexed for $3 \mathrm{~min}$ and then centrifuged for $5 \mathrm{~min}$ at $5000 \mathrm{rpm}$. Supernatants were diluted with $0.02 \mathrm{M}$ phosphoric acid and analysed by reverse-phase LC. Linearity of calibration for NCX4016 and metabolites was observed over the range $0.25-50 \mu \mathrm{g} / \mathrm{ml}$ with coefficients of determination greater than 0.9996. Extraction efficiency from spiked liver samples ranged from 85 to $95 \%$ for all the analytes. In the $\mathrm{S}$ $9000 \times g$ fraction, NCX4016 undergoes rapid metabolization, with the formation of salicylic acid (SA) and [3-(nitrooxymethyl)phenol] (HBN). HBN is then rapidly metabolised to 3-hydroxybenzylalcohol (HBA), and mainly to a new metabolic species, whose formation takes place specifically in the liver cell cytosol. LC-MS analysis (electrospray ionisation) of the cytosol extract in negative and positive-ion modes furnished deprotonated [M $-\mathrm{H}]^{-}$ and protonated $[\mathrm{M}+\mathrm{H}]^{+}$molecular ions at $m / z 412$ and 414, respectively, accompanied by the typical clusters with sodium. MS/MS analysis in negative-ion mode, by selection and collision of the ion at $m / z 412$, gave a fragmentation pattern characterized by the ions at $\mathrm{m} / \mathrm{z} 272$ and 254, which allowed to assign the structure of 1-(glutathion- $S$ yl)methylene-3-hydroxy-benzene, a conjugated product between GSH and the benzyl carbon atom of HBN. In rat liver cytosol HBN is completely metabolised to this thioether adduct within 30 min incubation; the process is enzymatically mediated by GSH transferase and strictly dependent on GSH availability. The relevance of this new metabolic pathway in NCX4016 detoxification by rat liver is discussed. (C) 2002 Elsevier Science B.V. All rights reserved.
\end{abstract}

Keywords: Nitroaspirin; NCX4016; In vitro metabolism; Rat liver; Liquid chromatography/ion trap mass spectrometry

\section{Introduction}

Benzoic acid, 2-(acetyloxy)-3-[(nitrooxy)methyl]phenyl ester (NCX4016) (Fig. 1), the ni-

* Corresponding author. Tel.: + 39-02-50317532; fax: + 3902-50317565

E-mail address: marina.carini@unimi.it (M. Carini). troderivative of aspirin, is the lead compound of a new class of NO-releasing non steroidal anti-inflammatory drugs (NO-NSAIDs). In pre-clinical 
studies the drug has been shown to display antiaggregatory and antithrombotic activity by a dual mechanism of action involving inhibition of cyclooxygenase (COX) and release of nitric oxide (NO), the latter acting on guanylate cyclase in both platelets and vascular smooth muscle cells $[1,2]$. The drug was also found to be devoid of typical toxic effects of COX-1 inhibitors (NSAIDs) on gastric mucosa also following repeated oral administration. This through inhibition of neutrophil adherence to vascular endothelium [3]. In addition, recent results indicated that NCX4016 is a powerful agent in improving the post-ischemic ventricular dysfunction in the rabbit heart [4] and in reducing the infarct size in rat heart induced by ischemia-reperfusion [5].

While the pharmacokinetic profile of the drug following single or repeated oral doses in the rat is known (no NCX4016 has been detected in plasma, but only salicylic acid) [2,6], no studies have been performed on its metabolism in vitro or in vivo in the animal.
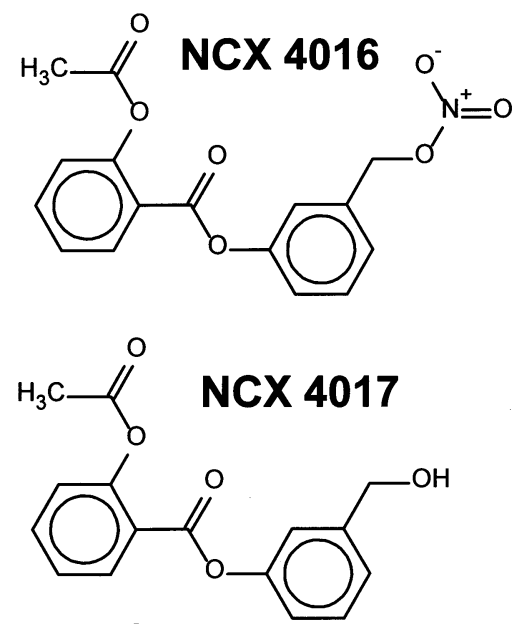

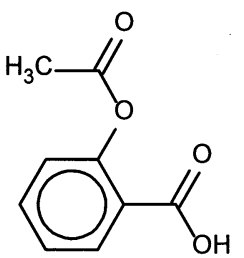

ASA

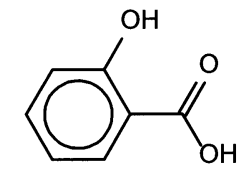

SA
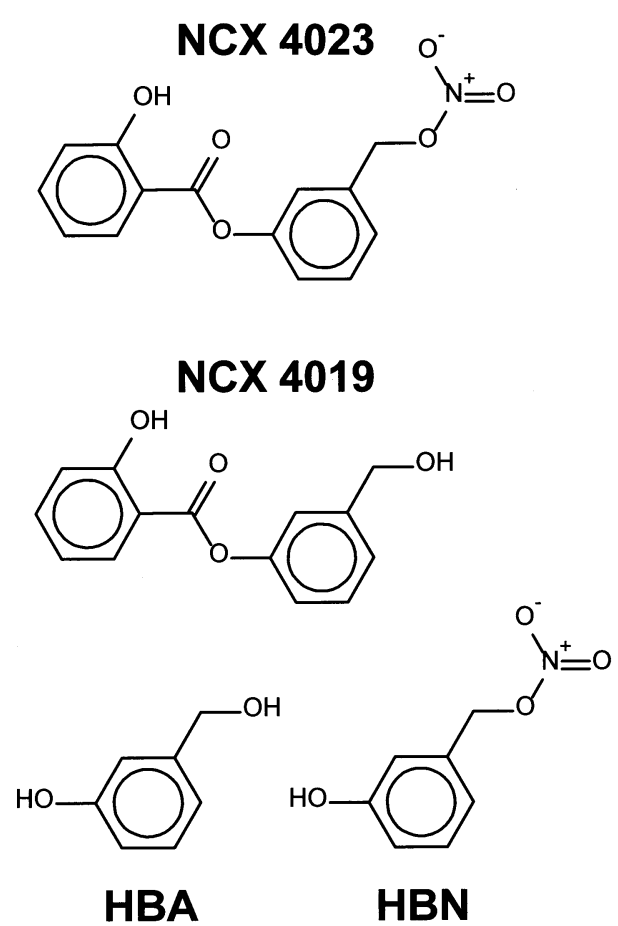

Fig. 1. Structures of NCX4016 and of some postulated metabolic products. 
2-(acetyloxy)-3-[(nitrooxy)methyl]phenyl ester (NO-ASA; NCX4016) and the NO-ASA metabolites: benzoic acid, 2-(hydroxy)-3-[(nitrooxy)methyl]phenyl ester (NCX4023), benzoic acid, 2-(acetyloxy)-3-(hydroxymethyl)phenyl ester (NCX4017), benzoic acid, 2-(hydroxy)-3-(hydroxymethyl)phenyl ester (NCX4019) and benzenemethanol,3-hydroxy- $\alpha$-nitrate $(\mathrm{HBN})$ were kindly provided by NICOX S.A. (Sophia Antipolis, France); benzenemethanol, 3-hydroxy (HBA), benzoic acid, 3-hydroxy (HBAC), acetylsalicylic acid (ASA), SA, glutathione (GSH), sulphobromophtalein (SBP) and $N$-ethylmaleimide (NEM) were purchased from Fluka Chimica (Milan, Italy); NADPH and NADH from Roche (Milan, Italy).

\subsection{Apparatus}

LC analyses were carried out on a Thermoquest Surveyor system equipped with a quaternary pump, a Surveyor UV/VIS Diode Array programmable detector 6000 LP model, a Surveyor AS autosampler, a vacuum degasser, and an Xcalibaur software. Separations were done by reversephase elution (Merck Licrosphere RP8 column; $25 \mathrm{~cm} \times 4.6 \mathrm{~mm}$ i.d.; particle size $5 \mu$ ) in the following conditions: gradient elution from $100 \%$ solvent A $\mathrm{CH}_{3} \mathrm{CN}$-water-phosphoric acid $(1: 9: 0.01, \mathrm{v} / \mathrm{v} / \mathrm{v})$ to $60 \% \mathrm{~B}\left(\mathrm{CH}_{3} \mathrm{CN}\right)$ in $30 \mathrm{~min}$; flow rate $1 \mathrm{ml} / \mathrm{min}$; UV-DAD detection (scan range $200-600 \mathrm{~nm}$; rate $0.5 \mathrm{scan} / \mathrm{s}$ ). LC-MS experiments were performed on a Finningan MAT (San Josè, CA) LCQ Duo Ion Trap mass spectrometer operating in atmospheric pressure ionisation fitted with an electrospray ionisation source (ESI), equipped with an orthogonal sampling adapter (compatible with non-volatile buffers) and connected to the LC system. The capillary temperature and the ionisation voltage were maintained at $250{ }^{\circ} \mathrm{C}$ and $4.5 \mathrm{kV}$, respectively. The mass spectrometer was operated in the negativeion and positive-ion modes, with a scan range from $m / z 200$ to 600 (scan rate 0.5 scans/s). Collision induced dissociation (CID) experiments in negative-ion mode were performed by resonant excitation by optimisation of the collision energy to $40 \%$.

\subsection{Standard solutions}

A stock solution of NCX4016, SA, HBN and HBA $\left(5 \mathrm{mg} / \mathrm{ml}\right.$ for each) was prepared in $\mathrm{CH}_{3} \mathrm{CN}$. This solution was further diluted with $\mathrm{CH}_{3} \mathrm{CN}$ to give a series of standards with concentrations of $5,10,20,50,200,500$ and $1000 \mu \mathrm{g} / \mathrm{ml}(0.25,0.5$, $1.0,2.5,10,25$ and $50 \mu \mathrm{g} / \mathrm{ml}$ in the hepatic tissue samples).

\subsection{In vitro studies}

Male Wistar rats (Charles-River, Calco, LC, Italy; $220 \pm 10 \times \mathrm{g}$ body weight) were maintained in compliance with the policy on animal care expressed in the National Research Council guidelines (NRC 1985). The animals were housed individually in stainless steel cages under standard conditions (temperature $22 \pm 2{ }^{\circ} \mathrm{C} ; \quad 50 \pm 10 \%$ relative humidity; artificial light from 06:00 to 20:00 h).

The animals, fasted overnight before experiments, were killed by cervical dislocation; the livers were immediately perfused with cold $\mathrm{NaCl}$ $(0.9 \%, \mathrm{w} / \mathrm{v})$, excised and minced in cold $\mathrm{KCl}$ $(1.15 \%, \mathrm{w} / \mathrm{v})$ and homogenized in $0.1 \mathrm{M}$ phosphate buffer, $\mathrm{pH}$ 7.4. Liver subcellular fractions $(9000 \times$ $g$ supernatant fraction, $105000 \times g$ supernatant fraction and microsomes) were prepared by differential centrifugation as previously described [7]. The microsomal pellets were washed once by homogenisation in $1.15 \% \mathrm{KCl}$ and recentrifuged at $105000 \times g$.

A volume of $0.05 \mathrm{ml}$ aliquots of NCX4016 working standard $\left(5 \mathrm{mg} / \mathrm{ml}\right.$ in $\left.\mathrm{CH}_{3} \mathrm{CN}\right)$ were added to rat liver subcellular fractions equivalent to $2.5 \mathrm{~g}$ of fresh liver tissue. After $5 \mathrm{~min}$ preincubation at $37{ }^{\circ} \mathrm{C}, 0.3 \mathrm{mM} \mathrm{MgCl}_{2}, 1.5 \mathrm{mM}$ NADPH, $1.5 \mathrm{mM} \mathrm{NADH}$ were added to the incubation mixture ( $5 \mathrm{ml}$ final volume). The mixtures were incubated in a metabolic shaker for different time periods up to $180 \mathrm{~min}$. At the end of each incubation time, $0.5 \mathrm{ml}$ aliquots were extracted with $\mathrm{CH}_{3} \mathrm{CN}$ (2 vol.) containing 1\% phosphoric acid ( $2 \mathrm{M}$ ), vortexed for $5 \mathrm{~min}$ and then centrifuged for $5 \mathrm{~min}$ at $5000 \mathrm{rpm}$. Supernatants were diluted to $2 \mathrm{ml}$ with $0.02 \mathrm{M}$ phosphoric acid and $50 \mu \mathrm{l}$ aliquots were submitted to LC analysis. 
In another set of experiments, HBA $(5 \mathrm{mg} / \mathrm{ml}$ in $\mathrm{CH}_{3} \mathrm{CN}$ ) was incubated up to $3 \mathrm{~h}$ at $37{ }^{\circ} \mathrm{C}$ with rat liver $\mathrm{S} 9000 \times g$ fractions (final concentration $50 \mu \mathrm{g} / \mathrm{ml}$ tissue sample) supplemented with 1.5 $\mathrm{mM}$ GSH or $1.5 \mathrm{mM} \mathrm{NADPH}$, and $\mathrm{HBN}$ (5 $\mathrm{mg} / \mathrm{ml}$ in $\mathrm{CH}_{3} \mathrm{CN}$ ) with cytosol (final concentration $50 \mu \mathrm{g} / \mathrm{ml}$ tissue sample). In the last case, incubations were carried out for $90 \mathrm{~min}$ in the presence or in the absence of $5 \mathrm{mM}$ NEM or 2 $\mathrm{mM}$ SBP. All the samples were extracted and processed as above described.

\subsection{Method validation}

The calibration lines were constructed by weighted $(1 / x)$ least-square linear regression analysis of the peak areas of analytes versus the concentrations. The calibration equation was used to calculate the concentration of analytes in the replicated and incubated samples. The precision and accuracy of the method were determined by the replicate analysis of S 9000 subcellular fraction samples containing the analytes at concentrations of $0.25,2.5,10$ and $50 \mu \mathrm{g} / \mathrm{ml}$ for NCX4016 and SA and of $0.5,2.5,10$ and $50 \mu \mathrm{g} / \mathrm{ml}$ for HBN and HBA in the calibration ranges. The accuracy was determined by calculating the relative error $(\mathrm{RE} \%)$ and the precision by the coefficient of variation $(\mathrm{CV} \%)$.

\subsection{Storage stability}

The storage stability of NCX4016, HBN, SA and HBA in rat liver tissue was studied by replicate analysis of S 9000 fraction extracts containing known amounts of analytes stored at $-20{ }^{\circ} \mathrm{C}$ for 4 weeks at concentrations of $0.5,10$ and 50 $\mu \mathrm{g} / \mathrm{ml}$.

\section{Results and discussion}

\subsection{In vitro studies}

In Fig. 1 are reported the structures of NCX4016 and of some postulated metabolites of the drug which could arise from different biotransformation pathways involving single or mul-
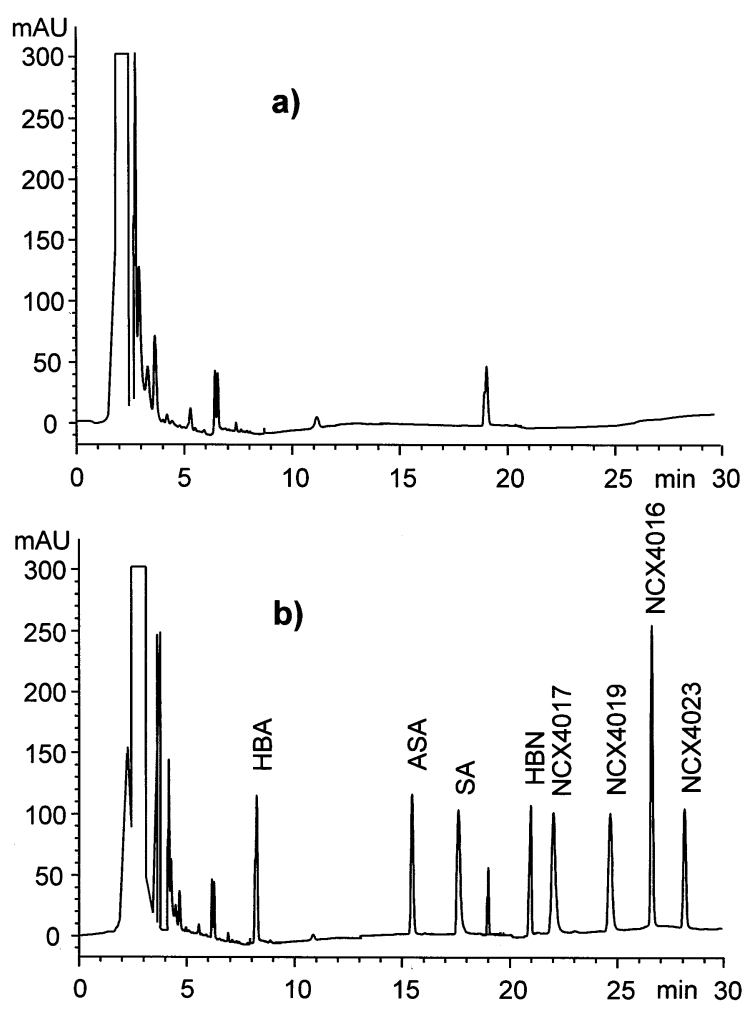

Fig. 2. HPLC separation of NCX4016 and its metabolites in liver tissue extracts. (a) Blank tissue (S $9000 \mathrm{~g}$ fraction); (b) $\mathrm{S}$ $9000 \mathrm{~g}$ fraction spiked with $5 \mu \mathrm{g} / \mathrm{ml}$ NCX4016, HBN, HBA and $2.5 \mu \mathrm{g} / \mathrm{ml} \mathrm{NCX4017,} \mathrm{NCX4019,} \mathrm{NCX4023,} \mathrm{ASA,} \mathrm{SA.}$

tiple hydrolytic cleavage of the different ester functions in the molecule (acetate, benzoate and nitrate esters). Firstly we developed a reversephase HPLC method for analysis of all the metabolites in liver samples. The chromatographic profile reported in Fig. $2 \mathrm{~b}$ is obtained from an extract of the native $\mathrm{S} 9000 \times g$ fraction spiked with a mixture of NCX4016 and metabolites, and shows that the employed gradient elution efficiently separated all the analytes with no interference from the blank matrix.

NCX4016 was then incubated with rat liver S $9000 \times g$ fraction (the more complete drug metabolising enzyme system) under aerobic conditions and in the presence of electrogenic cofactors $(\mathrm{NADPH}+\mathrm{NADH})$, and the formation of the metabolites was monitored by HPLC analysis with UV-DAD detection at $228 \mathrm{~nm}$ at different incubation times. 
SA, HBN and HBA and an unknown compound with RT 10.15 min were detected, but no one of the other postulated metabolites. This indicated that the most labile function in the molecule is the acetate ester (absence of acetylated derivatives NCX4017 and ASA), followed by the benzoate ester (no NCX4023), while the nitrate ester is more resistant to the enzymatic attack (no formation of NCX4019 and retention of HBN species).

The chromatographic profile of the extract relative to 90 min incubation (Fig. 3a) evidenced that HBN and HBA are minor metabolic species, while SA (RT $8.35 \mathrm{~min}$ ) and the unknown com-
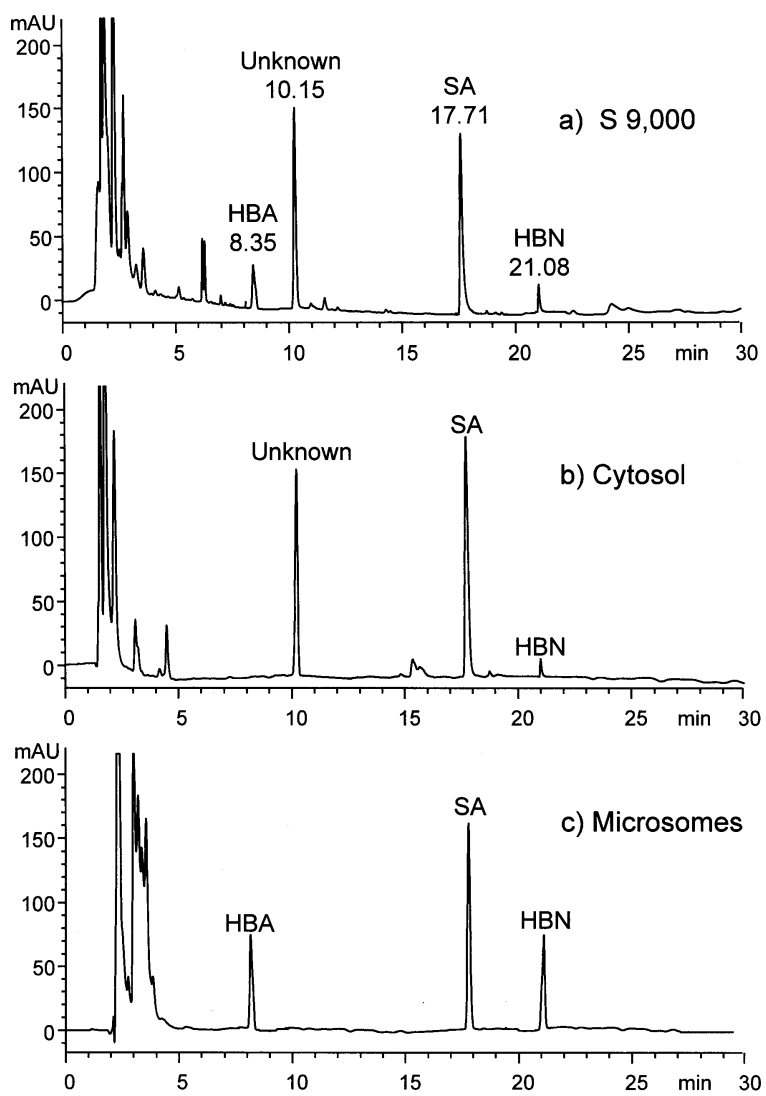

Fig. 3. Metabolization of NCX4016 by different rat liver subcellular fractions. The LC profiles refer to tissue samples (equivalent to $2.5 \mathrm{~g}$ fresh tissue) incubated for $90 \mathrm{~min}$ with 250 $\mu \mathrm{g}$ NCX4016, $1.5 \mathrm{mM}$ NADPH, $1.5 \mathrm{mM}$ NADH, $0.3 \mathrm{mM}$ $\mathrm{MgCl}_{2}$ (final volume $5 \mathrm{ml}$ ) and extracted as described in Methods. In cytosol incubates NADPH, NADH, and $\mathrm{MgCl}_{2}$ were omitted.

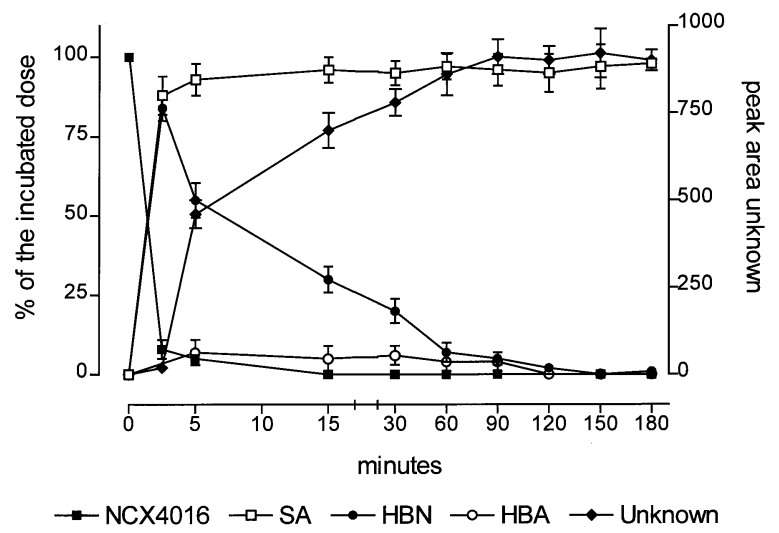

Fig. 4. Kinetics of NCX4016 metabolization by rat liver S $9000 \mathrm{~g}$ subcellular fraction. S $9000 \mathrm{~g}$ fraction equivalent to 2.5 $\mathrm{g}$ fresh tissue was incubated with $250 \mu \mathrm{g}$ NCX4016, $1.5 \mathrm{mM}$ NADPH, $1.5 \mathrm{mM} \mathrm{NADH}, 0.3 \mathrm{mM} \mathrm{MgCl}_{2}$ (final volume 5 $\mathrm{ml}$ ). At different incubation times, $0.5 \mathrm{ml}$ aliquots were extracted and processed as described in Methods. Each value is the mean \pm S.D. of five independent experiments.

pound (RT $10.15 \mathrm{~min}$ ) are the most abundant. The kinetics of NCX4016 metabolization determined by quantitation of the drug and its known metabolites in $\mathrm{S} 9000 \times g$ samples at different incubation times (Fig. 4) indicated that nitroaspirin undergoes complete biotransformation to $\mathrm{SA}$ and $\mathrm{HBN}$ within the first $5 \mathrm{~min}$, due to the cleavage of the acetate and the benzoate esters. While SA is a final metabolite (maximal increase within $5 \mathrm{~min}$ and plateau between 5 and $15 \mathrm{~min}$ ), HBN is rapidly metabolised to the unknown metabolic species, whose formation is maximal at 90 min and strictly parallels the kinetics of HBN disappearance. Only in minimal amount $\mathrm{HBN}$ is converted to HBA.

In order to identify the cellular compartment and the enzyme system involved, S 9000 was fractionated into microsomes and cytosol, and NCX4016 was incubated with both subcellular fractions for a fixed time period (90 $\mathrm{min}$ ). The unknown metabolite is formed in cytosol but not in microsomes; conversely HBA is absent in cytosol, but present in microsomes as final metabolic product (Fig. 3).

Hence, the extract from cytosol incubated with nitroaspirin was analysed by LC coupled to mass 
spectrometry with ES ionisation interface, a soft ionisation technique which furnishes unequivocal information on molecular weight. The peak with RT 10.15 min showed an UV-DAD profile (Fig. 5 a insert) typical of a phenol derivative with $\lambda_{\max }$ at $276 \mathrm{~nm}$, which was superimposable to those of $\mathrm{HBN}$ or HBA; in the negative-ion mode, it gave a deprotonated molecular anion at $m / z$ 412, confirmed by the typical clusters with sodium or potassium (Fig. 5b and c) and by the selected ion chromatogram (SIC) relative to this ionic species (Fig. 5d).
Molecular weight was confirmed by recording the mass spectrum in the positive-ion mode (Fig. 6a) which furnished a quasi molecular ion $[\mathrm{M}+$ $\mathrm{H}^{+}$at $m / z 414$ and a cationized molecular ion $[\mathrm{M}+\mathrm{Na}]^{+}$at $m / z$ 436. Structure elucidation was achieved by MS/MS experiments in negative-ion mode, by selection and collision of the ion at $\mathrm{m} / \mathrm{z}$ 412 (Fig. 6b): the fragmentation pattern, with the ions at $\mathrm{m} / \mathrm{z} 272$ and 254 allowed to assign the structure of 1-(glutathion- $S$-yl)methylene-3-hydroxy-benzene, a thioether conjugated product between GSH and the benzyl carbon atom of


Fig. 5. LC-MS analysis of cytosol extract (90 min incubation). (a) LC-UV-DAD profile (insert: UV spectrum of the peak with R.T. $10.15 \mathrm{~min})$; (b) Total ion current chromatogram $(\mathrm{m} / z$ 200-600); (c) negative-ion ESI mass spectrum; (d) selected ion chromatogram (SIC) of $[\mathrm{M}-\mathrm{H}]^{-}$at $m / z 412$. 

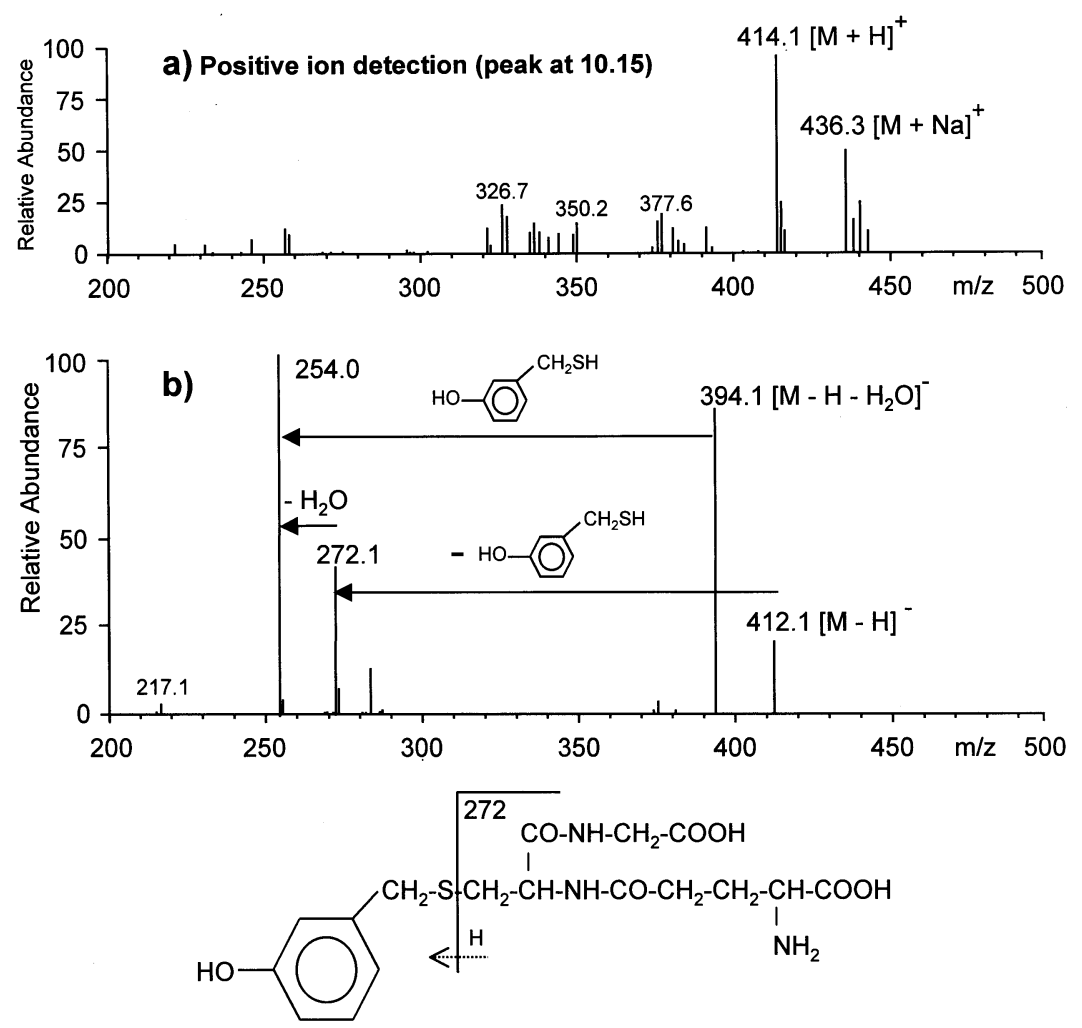

Fig. 6. Positive-ion ESI mass spectrum of the peak with R.T. 10.15 min (a) and CID (collision-induced dissociation) mass spectrum of the $[\mathrm{M}-\mathrm{H}]^{-}$at $m / z 412$ in negative-ion mode (b).

HBA or HBN. To gain a deeper insight into the mechanism of its formation, HBA was incubated with the $\mathrm{S} 9000 \times g$ fraction: no conjugated metabolite was detected at any observation time, even in the presence of high concentrations of GSH $(5 \mathrm{mM})$. As shown in Fig. 7 and Table 1, the only metabolite which arised from HBA in the $\mathrm{S} 9000 \times g$ fraction was its oxidation product, 3-hydroxybenzoic acid (HBAC; R.T. $11.52 \mathrm{~min}$ ), identified by comparison with the chromatographic properties of the standard. The formation of the latter compound requires electrogenic cofactors (NADPH, NADH; i.e. cytochrome P-450 involvement) and proceeds with an extremely low kinetics (only the $23 \%$ of the incubated dose is oxidized after $3 \mathrm{~h}$ incubation). This unequivocally excludes HBA as direct precursor of the thioether metabolite and point to a role for HBN. Incubation of HBN with rat liver cytosol (Table 2) demonstrates that the compound is completely metabolised to the thioether derivative within 30 min: the process is enzymatically mediated, since no metabolite is observed in inactivated cytosol (by heating at $100{ }^{\circ} \mathrm{C}$ ), even in the presence of high GSH concentrations. The conjugation process is inhibited by NEM (a well known alkylating agent for thiols) or by SBP (a typical inhibitor of GSH-transferases) to confirm the strict dependence on GSH availability and on an enzyme system belonging to the family of GSH-Stranferases.

Hence the metabolite arises from HBN through the nucleophilic displacement by GSH of the easily leaving $\mathrm{ONO}_{2}{ }^{-}$group from the highly electrophilic benzyl carbon atom. The poorer leaving ability of the primary $\mathrm{OH}$ group in HBA explains why this compound does not react with GSH and it is not the precursor of the thioether. 
This new metabolic pathway, which seems specifically linked to the cytosol compartment of the liver cell, and to the chemical structure of the spacer of NCX4016, is quite unusual and can be considered alternative to that commonly proposed for organic nitrates used in cardiovascular therapy (i.e. nitroglycerin), where the nitrate ester enzymatically trans-esterificate GSH with formation of $\mathrm{GSNO}_{2}$ and of the corresponding alcohol [8]. On the other hand, HBA from NCX4016 in S $9000 \times g$ fraction or microsomes may arise from this conventional metabolic pathway or from a cytochrome P-450 mediated denitration process [9].

\subsection{Linearity of calibration}

S $9000 \times g$ fraction samples spiked with the analytes to give concentrations of $0.25,0.5,1.0$,
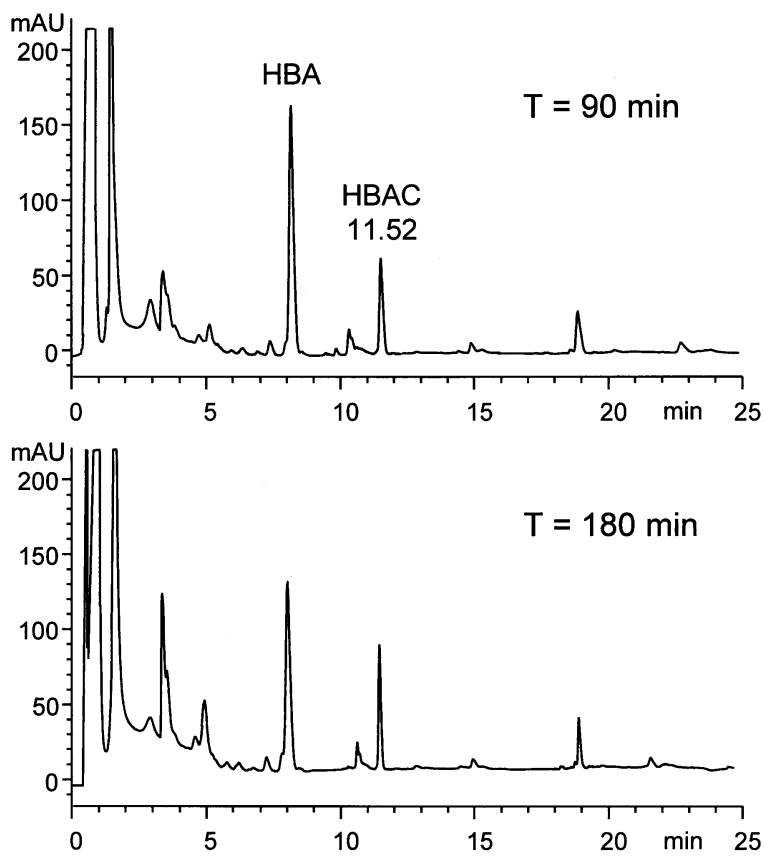

Fig. 7. LC-UV-DAD profiles of S $9000 \mathrm{~g}$ subcellular fraction incubated with HBA.S $9000 \mathrm{~g}$ fraction equivalent to $2.5 \mathrm{~g}$ fresh tissue was incubated with $250 \mu \mathrm{g} \mathrm{HBA}, 1.5 \mathrm{mM}$ NADPH, 1.5 $\mathrm{mM} \mathrm{NADH}, 0.3 \mathrm{mM} \mathrm{MgCl}$ (final volume $5 \mathrm{ml}$ ). At different incubation times, $0.5 \mathrm{ml}$ aliquots were extracted and processed as described in Methods. Each value is the mean \pm S.D. of five independent experiments.
Table 1

Time-course of HBA metabolization by S $9000 \times g$ fraction

\begin{tabular}{lll}
\hline $\begin{array}{l}\text { Incubation time } \\
(\mathrm{min})\end{array}$ & 3-Hydroxybenzoic acid formation \\
& & \\
\cline { 2 - 2 } & $\%$ of the incubated & nmoles/g tissue \\
& dose & \\
& & \\
\hline 15 & - & - \\
30 & $2.5 \pm 0.6$ & $10.1 \pm 1.2$ \\
60 & $7.1 \pm 0.9$ & $28.1 \pm 1.8$ \\
90 & $12.4 \pm 1.3$ & $49.6 \pm 2.6$ \\
120 & $18.7 \pm 2.1$ & $74.8 \pm 4.2$ \\
180 & $23.5 \pm 1.8$ & $94.1 \pm 3.6$ \\
\hline
\end{tabular}

$\mathrm{S} 9000 \times \mathrm{g}$ fraction equivalent to $2.5 \mathrm{~g}$ fresh tissue was incubated with $250 \mu \mathrm{g}$ HBA, $1.5 \mathrm{mM}$ NADPH, $1.5 \mathrm{mM} \mathrm{NADH}$, $0.3 \mathrm{mM} \mathrm{MgCl}$ (final volume $5 \mathrm{ml}$ ). At different incubation times, $0.5 \mathrm{ml}$ aliquots were extracted and processed as described in Section 2 (final volume $2.0 \mathrm{ml}$ ). The formation of HBAC was determined by measuring the disappearance of HBA. Each value is the mean \pm S.D. of five independent experiments.

2.5, 10, 25 and $50 \mu \mathrm{g} / \mathrm{ml}$ for NCX4016 and SA and of $0.5,1.0,2.5,10,25$ and $50 \mu \mathrm{g} / \mathrm{ml}$ for HBN and HBA were analysed. For each compound the standard response was linear over the entire calibration range, with correlation coefficients greater than 0.9995 . The equations of the calibration lines were as follows: $y=1407.1 x+25.6\left(r^{2}=0.9996\right)$ for NCX4016; $y=571.5 x+14.6\left(r^{2}=0.9999\right)$ for HBN; $y=493 x+126\left(r^{2}=0.9998\right)$ for HBA; $y=$ $1109 x-403\left(r^{2}=0.9996\right)$ for SA.

\subsection{Precision and accuracy}

The intra-assay precision and accuracy of the method were determined by analysing six replicates at four concentration levels for each compound, and the relative data are summarized in Table 3. The RE of NCX4016 and SA at 0.25 $\mu \mathrm{g} / \mathrm{ml}$ were -10 and $-5.2 \%$, respectively, and those of $\mathrm{HBN}$ and $\mathrm{HBA}$ at $0.5 \mu \mathrm{g} / \mathrm{ml}$ were -4.0 and $+3.0 \%$. The CV of NCX4016 and SA at 0.25 $\mu \mathrm{g} / \mathrm{ml}$ were 6.48 and $7.80 \%$, respectively, and those of HBN and HBA at $0.5 \mu \mathrm{g} / \mathrm{ml}$ were 4.95 and $8.28 \%$. Hence the limits of quantitation of NCX4016, SA, HBN and HBA were determined as $0.25,0.25,0.5$ and $0.5 \mu \mathrm{g} / \mathrm{ml}$, respectively, as the lowest concentrations that can be determined 
with an acceptable accuracy of $\pm 20 \%$ and a precision below $20 \%$.

The intermediate precision and accuracy were determined at the same concentrations (3 days). The accuracy for all the analytes (Table 4) ranged from -5.2 to $+4.0 \%$ of nominated concentrations with precision ranging from 1.75 to $7.82 \%$ over the concentration ranges evaluated.

\subsection{Extraction efficiency and storage stability}

The recovery test was performed by comparing the response of extracted samples spiked with NCX4016 and metabolites before extraction with that of extracted blank samples spiked just before injection (to compensate for any effect due to the matrix). Percentage recoveries, determined at the two extremes of the calibration ranges $(n=6$

Table 2

HBN metabolization by rat liver cytosol: relative amounts of the conjugated product formed

\begin{tabular}{lll}
\hline $\begin{array}{l}\text { Incubation } \\
\text { time/conditions }\end{array}$ & Conjugate product formation \\
\cline { 2 - 3 } & Relative $\%$ & nmoles/g tissue \\
\hline $105000 \times g(5 \mathrm{~min})$ & $32.7 \pm 2.4$ & $96.7 \pm 7.1$ \\
$105000 \times g(10 \mathrm{~min})$ & $59.3 \pm 4.9$ & $175.4 \pm 14.5$ \\
$105000 \times g(15 \mathrm{~min})$ & $78.5 \pm 6.8$ & $232.2 \pm 20.2$ \\
$105000 \times g(30 \mathrm{~min})$ & 100 & $295.8 \pm 24.4$ \\
$105000 \times g$ inactivated & - & - \\
by heating at $100{ }^{\circ} \mathrm{C}$ & & - \\
$105000 \times g$ inactivated & - & \\
by heating at & & - \\
$100{ }^{\circ} \mathrm{C}+5 \mathrm{mM} \mathrm{GSH}$ & & - \\
$105000 \times g(30 \mathrm{~min})$ & - & \\
$+5 \mathrm{mM} \mathrm{NEM}$ & & \\
$105000 \times g(30 \mathrm{~min})$ & - & \\
$+2 \mathrm{mM}$ SBP & &
\end{tabular}

$105000 \times g$ fraction equivalent to $2.5 \mathrm{~g}$ fresh tissue was incubated with $250 \mu \mathrm{g} \mathrm{HBN}$ in the presence or in the absence of different activators/inhibitors. At different incubation times, $0.5 \mathrm{ml}$ aliquots were extracted and processed as described in Section 2 (final volume $2.0 \mathrm{ml}$ ). The formation of the conjugated product was determined by measuring the disappearance of $\mathrm{HBN}$. Each value is the mean \pm S.D. of five independent experiments. SBP, sulphobromophtalein; NEM, $N$-ethylmaleimide. each) were satisfactory, ranging from 85 to $95 \%$ for all the compounds (data not shown). The storage stability of NCX 4016 and its metabolites in rat liver tissue extracts was determined at $-20{ }^{\circ} \mathrm{C}$ using $\mathrm{S} 9000 \times g$ fraction samples spiked with the analytes (NCX4016, SA, HBN, HBA) at $0.5,2.5$ and $50 \mu \mathrm{g} / \mathrm{ml}(n=3)$. The recoveries were from 92.4 to $102.7 \%$ for all the analytes, to indicate that they were stable for at least 4 weeks in tissue extracts when stored at $-20{ }^{\circ} \mathrm{C}$.

\section{Conclusions}

A reliable HPLC assay for the simultaneous determination of NCX 4016 and its metabolites in liver tissue has been developed, which provides satisfactory accuracy and precision for all the analytes. The method has been successfully applied to the study of the in vitro metabolism of the drug by rat liver, to get an insight into the key metabolic steps of its hepatic biotransformation and detoxification and seems to be applicable also to the study of the in vivo metabolism of the drug. Although preliminary, the results of this study, in particular the formation of the glutathione conjugate, can explain some hardly reconcilable findings raised by previous pharmacokinetics studies of others and us $[2,6,10]$ after oral administration of the drug in the rat

- low or none systemic bioavailablity of the drug: no circulating parent compound

- presence in plasma of SA only, and no other metabolic species found

- slow NO release.

We can postulate that the drug, which is stable in the stomach under acidic conditions [11], is largely absorbed by the small intestine, reaches the liver, where undergoes substantial first pass effect to be metabolised to SA and HBN; this last to the thioether adduct which in vivo will follow the typical metabolic pathway of glutathione conjugates (degradation to mercapturic acid derivatives and excretion in urines) and in lesser extent to HBA which will undergo rapid conjugation with glucuronic/sulphuric acid (urines). The massive $\mathrm{HBN}$ sequestration by the liver in the form of the thioether adduct results in a spreading of 
nitrate species which can be excreted by the hepatocyte as such or undergo a step-by-step conversion by liver reductases to bioactive NO. This can explain the limited and slow release of $\mathrm{NO}$ from NCX4016 observed in vivo: as recently evidenced by us [10], the nitrosylhemoglobin [HbFe(II)NO] complex, unequivocal marker of in vivo NO formation, is in fact detectable in blood of rats orally treated with NCX4016 $(100,200 \mathrm{mg} / \mathrm{Kg})$ only $1 \mathrm{~h}$ after drug administration and peaks between 4-6 h.

Table 3

Intra-assay precision and accuracy for determination of NCX4016 and its metabolites in rat liver S $9000 \times g$ fraction

\begin{tabular}{|c|c|c|c|c|}
\hline Compound & Nominal concentration $(\mu \mathrm{g} / \mathrm{ml})$ & Mean measured concentration $(\mu \mathrm{g} / \mathrm{ml})$ & $\mathrm{CV} \%$ & $\mathrm{RE} \%$ \\
\hline NCX4016 & $\begin{array}{c}0.250 \\
2.500 \\
10.00 \\
50.00\end{array}$ & $\begin{array}{c}0.224 \\
2.463 \\
10.08 \\
49.75\end{array}$ & $\begin{array}{l}6.48 \\
4.05 \\
3.68 \\
2.41\end{array}$ & $\begin{array}{r}-10.0 \\
-1.48 \\
+0.80 \\
-0.50\end{array}$ \\
\hline SA & $\begin{array}{c}0.250 \\
2.500 \\
10.00 \\
50.00\end{array}$ & $\begin{array}{c}0.237 \\
2.473 \\
10.12 \\
49.40\end{array}$ & $\begin{array}{l}7.80 \\
5.20 \\
2.75 \\
2.40\end{array}$ & $\begin{array}{l}-5.20 \\
-1.08 \\
+1.20 \\
-1.20\end{array}$ \\
\hline $\mathrm{HBN}$ & $\begin{array}{c}0.500 \\
2.500 \\
10.00 \\
50.00\end{array}$ & $\begin{array}{c}0.480 \\
2.522 \\
9.80 \\
50.50\end{array}$ & $\begin{array}{l}4.95 \\
5.06 \\
3.12 \\
1.82\end{array}$ & $\begin{array}{l}-4.00 \\
+0.88 \\
-2.00 \\
+1.00\end{array}$ \\
\hline HBA & $\begin{array}{c}0.500 \\
2.500 \\
10.00 \\
50.00\end{array}$ & $\begin{array}{c}0.515 \\
2.470 \\
9.65 \\
50.35\end{array}$ & $\begin{array}{l}8.28 \\
3.15 \\
1.80 \\
2.12\end{array}$ & $\begin{array}{l}+3.00 \\
-1.20 \\
-3.50 \\
+0.70\end{array}$ \\
\hline
\end{tabular}

Six replicates at each level. Coefficient of variance in percentage $(\mathrm{CV} \%)$. Relative error $(\mathrm{RE} \%)$.

Table 4

Inter-assay precision and accuracy for determination of NCX4016 and its metabolites in rat liver S $9000 \times g$ fraction

\begin{tabular}{|c|c|c|c|c|}
\hline Compound & Nominal concentration $(\mu \mathrm{g} / \mathrm{ml})$ & Mean measured concentration $(\mu \mathrm{g} / \mathrm{ml})$ & $\mathrm{CV} \%$ & $\mathrm{RE} \%$ \\
\hline \multirow[t]{4}{*}{ NCX4016 } & 0.250 & 0.237 & 7.82 & -5.20 \\
\hline & 2.500 & 2.548 & 5.45 & +1.92 \\
\hline & 10.00 & 9.840 & 2.28 & -1.60 \\
\hline & 50.00 & 50.05 & 1.75 & +0.10 \\
\hline \multirow[t]{4}{*}{ SA } & 0.250 & 0.260 & 5.32 & +4.00 \\
\hline & 2.500 & 2.530 & 3.27 & +1.20 \\
\hline & 10.00 & 10.06 & 3.98 & +0.60 \\
\hline & 50.00 & 49.88 & 2.72 & -0.24 \\
\hline \multirow[t]{4}{*}{$\mathrm{HBN}$} & 0.500 & 0.487 & 6.58 & -2.60 \\
\hline & 2.500 & 2.463 & 4.90 & -1.48 \\
\hline & 10.00 & 9.90 & 5.02 & -1.00 \\
\hline & 50.00 & 49.78 & 3.65 & -0.44 \\
\hline \multirow[t]{4}{*}{ HBA } & 0.500 & 0.507 & 7.14 & +1.40 \\
\hline & 2.500 & 2.480 & 5.21 & -0.80 \\
\hline & 10.00 & 10.07 & 2.48 & +0.70 \\
\hline & 50.00 & 50.15 & 1.95 & +0.30 \\
\hline
\end{tabular}

Six runs, duplicates at each level in each run over a period of 3 days. Coefficient of variance in percentage $(\mathrm{CV} \%)$. Relative error $(\mathrm{RE} \%)$. 


\section{Acknowledgements}

Financial support from MURST (Cofinanziamento Programma Nazionale 2000) is gratefully acknowledged.

\section{References}

[1] P.M. Minuz, V. Zuliani, S. Gaino, R. Tommasoli, A. Lechi, Cardiovasc. Drug Rev. 16 (1998) 31-47.

[2] J.L. Wallace, M.N. Muscara, W. McKnight, M. Dicay, P. Del Soldato, G. Cirino, Thromb. Res. 93 (1999) 43-50.

[3] J.L. Wallace, W. McKnight, T.L. Wilson, P. Del Soldato, G. Cirino, Am. J. Physiol. 273 (1997) G1246-G1251.

[4] G. Rossoni, M. Berti, V. De Gennaro Colonna, M. Bernareggi, P. Del Soldato, F. Berti, Ital. Heart J. 1 (2000) 146-155.
[5] G. Rossoni, B. Manfredi, V. De Gennaro Colonna, M. Bernareggi, F. Berti, J. Pharmacol. Exp. Ther. 297 (2001) $380-387$.

[6] L. Cuzzolin, A. Adami, M. Degan, F. Crivellente, S. Bonapace, P. Minuz, G. Benoni, Life Sci. 58 (1996) 207-210.

[7] R. Maffei Facino, M. Carini, O. Tofanetti, Arzneim. Forsch./Drug Res. 36 (1986) 722-728.

[8] K.E. Hill, R.W. Hunt, R. Jones, R.L. Hoover, R.F. Burk, Biochem. Pharmacol. 43 (1992) 561-566.

[9] D. Servent, M. Delaforge, C. Ducrocq, D. Mansuy, M. Lenfant, Biochem. Biophys. Res. Commun. 163 (1989) 1210-1216.

[10] M. Carini, G. Aldini, R. Stefani, M. Orioli, R. Maffei Facino, J. Pharm. Biomed. Anal. 26 (2001) 509-518.

[11] M. Carini, G. Aldini, R. Stefani, R. Maffei Facino, G. Rossoni, P. Del Soldato, Joint Meeting of the VII World Conference on Clinical Pharmacology and Therapeutics IUPHAR and Fourth Congress of the European Association for Clinical Pharmacology and Therapeutics (EACPT), Florence, July 15-20, 2000. 